\title{
On the Pilger Rolling of Zr-4 Alloy: Finite Element Modeling and Plastic Deformation Behavior
}

\author{
He Weijun ${ }^{1,2}$, Yuan Gaihuan ${ }^{2,3}$ Luan Baifeng ${ }^{1}, \quad$ Wang Lian ${ }^{2,3}, \quad$ Chu Linhua ${ }^{2}$, \\ Liu Qing ${ }^{1}$ \\ ${ }^{1}$ Chongqing University, Chongqing 400044, China; ${ }^{2}$ State Nuclear Baoti Zirconium Industry Co., Ltd, Baoji 721013, China; ${ }^{3}$ Shaanxi Key \\ Laboratory of Nuclear Grade Zirconium, Baoji 721013, China
}

\begin{abstract}
Pilger rolling process has a specific influence on the mechanical properties and texture of zirconium alloy cladding tube. Due to its complexity, experimental research on the Pilger rolling process would be very costly. Therefore, a 3D finite element model was built to simulate Pilger rolling with ABAQUS/standard package. Simulation of a full pass of Pilger rolling of Zr-4 alloy tube, including a series of forward strokes and backward strokes, was carried out. The results show that the predicted tube sizes agree well with the experimental results. Additionally, the simulated rolling force also matches well with the force calculated by classic empirical formula, which validates the accuracy of the proposed model. The simulation results show that the stress and strain states in groove-side are different from that in groove-bottom. Moreover, large shear deformation happens in the rolled tube. The simulated shear strain displays substantial fluctuations during rolling, which are attributed to the cyclic position change of element (material point) with respect to the groove-side.
\end{abstract}

Key words: zirconium alloy; Pilger rolling; finite element modeling; plastic deformation behavior

Due to their good corrosion resistance and low neutron absorption, zirconium alloys are widely used in the field of nuclear energy ${ }^{[1-4]}$. Zirconium alloy (zircaloy) cladding tubes are generally fabricated by Pilger rolling process, in which the material undergoes a series of small deformations and alternated stress states. In the past several decades, researches on the Pilger rolling explored its influence on the microstructure and mechanical properties of zircaloy cladding tube. Montmitonnet et al. ${ }^{[5]}$ investigated the evolution of the internal surface topography (plateaux and valleys) of cold pilgered zircaloy tube and found that the higher the rolling force (or contact stress), the higher the proportion of plateaux for a given tool and lubrication. Girard et al. ${ }^{[6]}$ carried out experimental and numerical research on the effect of plastic shearing on damage and texture of Zr-4 cladding tube. By tracking the microstructure of zirconium alloy tubes subjected to interrupted pilgering with electron backscattered diffraction
(EBSD), Allen et al. ${ }^{[7]}$ analyzed the influence of $Q$-factor (the ratio of the reduction in thickness to reduction in diameter) on the evolution of texture. Based on a series of experiments and numerical simulations, Abe et al. ${ }^{[8,9]}$ reported that circumferential-direction compression was an effective method to evaluate the cold workability of $\mathrm{Zr}-4$ tube in cold Pilger rolling. Mukherjee et al. ${ }^{[10]}$ characterized the grain size, micro-strain and dislocation density of $\mathrm{Zr}-2$ fabricated by Pilger rolling with X-ray diffraction line profile analysis.

Since varied three dimensional stress states are involved in Pilger rolling, it is not easy to use experiments to investigate the material deformations as in Pilger rolling, and thus numerous numerical simulations were carried out. Aubin et al. ${ }^{[11]}$ proposed a three dimensional analytic model to describe the Pilger rolling, in which the stress and strain field can be quickly calculated. Mulot et al. ${ }^{[12]}$ performed finite element modeling of Pilger rolling based on rigid plasticity model and

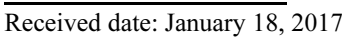

Foundation item: National Natural Science Foundation of China (51421001); Chongqing Natural Science Foundation (cstc2014jcyjA50022); Fundamental Research Funds for the Central University (106112015CDJXY130002)

Corresponding author: Luan Baifeng, Ph. D., Professor, College of Materials Science and Engineering, Chongqing University, Chongqing 400044, P. R. China, Tel: 0086-23-65106067, E-mail: bfluan@cqu.edu.cn 
pointed out that the predicated stress field was more accurate than the result calculated with analytic model. Montmitonnet et al. ${ }^{[13]}$ carried out elastic-plastic modeling of cold Pilger rolling of zircaloy tube and reported that one stroke of simulation was sufficient to analyze the whole process in the case of non-work hardening material. Lodej et al. [14] developed a post-processing tool to compute the successive positions of material point by cumulating the single-stroke displacements and the rigid body motions (feeding and rotation) between strokes. Gurao et al. ${ }^{[15]}$ studied the evolution of crystallographic texture during pilgering of $\mathrm{Zr}-4$ by experiments and crystal plasticity modeling.

However, most of the aforementioned numerical researches on Pilger rolling only carried out one or several strokes. Moreover, the backward stroke (return stroke) was generally ignored, thus leading to sever limitation in description of the stress and strain states. Therefore, in this work, three dimensional (3D) elastic-plastic modeling, including more than 70 forward and backward strokes, was performed to analyze the stress and strain states of $\mathrm{Zr}-4$ tube, from mother tube to final tube. Different stages of deformation were investigated. Cyclic shear strain were first observed and discussed.

\section{Finite Element Model}

\subsection{Model's geometry}

The principle of two-rollers Pilger rolling has been detailed by Huang et al. ${ }^{[16]}$. Based on ABAQUS/standard package, the built model is shown in Fig.1. Three kinds of components are included in the model: one tube, one mandrel and two rollers. The initial tube size is $\Phi 17.78 \mathrm{~mm} \times 2.30 \mathrm{~mm}$ and discretized by 7448 C3D8R elements. The rollers and the mandrel are assumed to be rigid body. During rolling, with the rotation of rollers, the elliptic groove of the roller becomes smaller and smaller and forces the reduction of tube's outer diameter. The diameter of the mandrel is gradually decreased along the longitudinal direction, which controls the evolution of tube's inner diameter.

\subsection{Movement of rollers and tube}

There are four kinds of movement in Pilger rolling: the translation and the rotation of the rollers, the feeding and the rotation of the tube. The translation of the rollers is driven by a slider-crank system, as shown in Fig.2. There are two limit locations for the roller's translation, namely the forward and

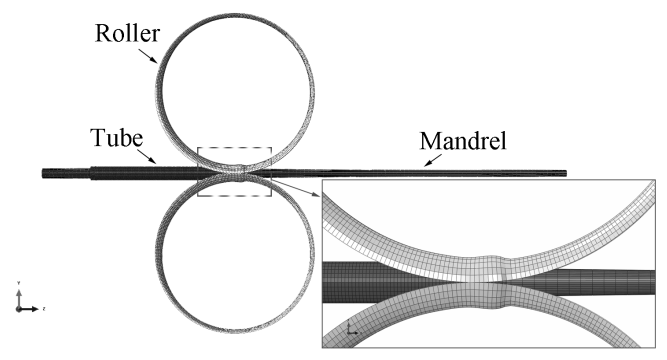

Fig.1 Finite element model for pilgering rolling of Zr-4 alloy backward limit locations. When rollers move from forward to backward limit location, it is forward stroke. Inversely, when rollers move from backward to forward limit location, it is called as backward stroke. According to the principle of slider-crank system, we can calculate the displacement-time curve of the rollers, as displayed in Fig.3a. There are cooperating-gears on the slideway and the axis of the rollers. The translation of the rollers will cause their rotation. Therefore, the rotation has a specific relationship with the translation:

$\omega_{\text {rotation speed }} R_{\text {Pitch radius }}=V_{\text {translation speed }}$

So, based on the displacement-time curve of the roller, the rotation-time curve can also be computed, as shown in Fig. $3 \mathrm{~b}$.

For the tube, the feeding rate is $2 \mathrm{~mm} / \mathrm{stroke}$. The feeding occurs once when the rollers are at the forward limit location. While, there are two rotations in each stroke, by $31^{\circ}$ and $26^{\circ}$ when the rollers are at forward and backward limit location, respectively. The displacement-time curve and rotation-time curve of the tube are shown in Fig.3c and Fig.3d, respectively. It is worth noting that Fig.3 only shows movement-time curves during the first ten strokes, for the sake of clarity. In the simulation, movement-time information of more than 80 stokes has been calculated and implemented in ABAQUS/ standard package in order to achieve representative modeling of Pilger rolling.

\subsection{Material properties}

To obtain the elastic and plastic properties of $\mathrm{Zr}-4$ tube, uniaxial tensile tests along the longitudinal direction were carried out. The tests were quasi-static and repeated three times to ensure the reproducibility of the data. The true stress-true strain curve is displayed in Fig.4. Obvious necking appeared at $20 \%$ elongation, preventing getting true stress-strain data at higher strain. However, during the rolling pass from $\Phi 17.78 \mathrm{~mm} \times 2.30 \mathrm{~mm}$ to $\Phi 10.02 \mathrm{~mm} \times 0.72 \mathrm{~mm}$, the wall thickness and outer diameter reduction reach $68 \%$ and $44 \%$, respectively. Mechanical data at larger strain are needed; so linear extrapolation based on the experimental data was made, as shown in Fig.4. The Young's modulus is 92.6 GPa and the Poisson ratio is 0.31 .

In the current model, the effects of temperature and strain rate were ignored. Coulomb friction model, with friction cofficient of $0.06^{[17]}$, was employed in the simulation.

\section{Model Validation}

After about 70 strokes of rolling, the elements at the front end of the tube reach the area of size fixing (near the end of

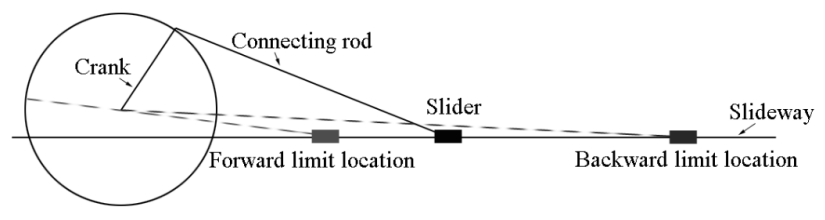

Fig.2 Schematic illustration of the Slider-crank system that drives the translation of rollers during Pilger rolling 

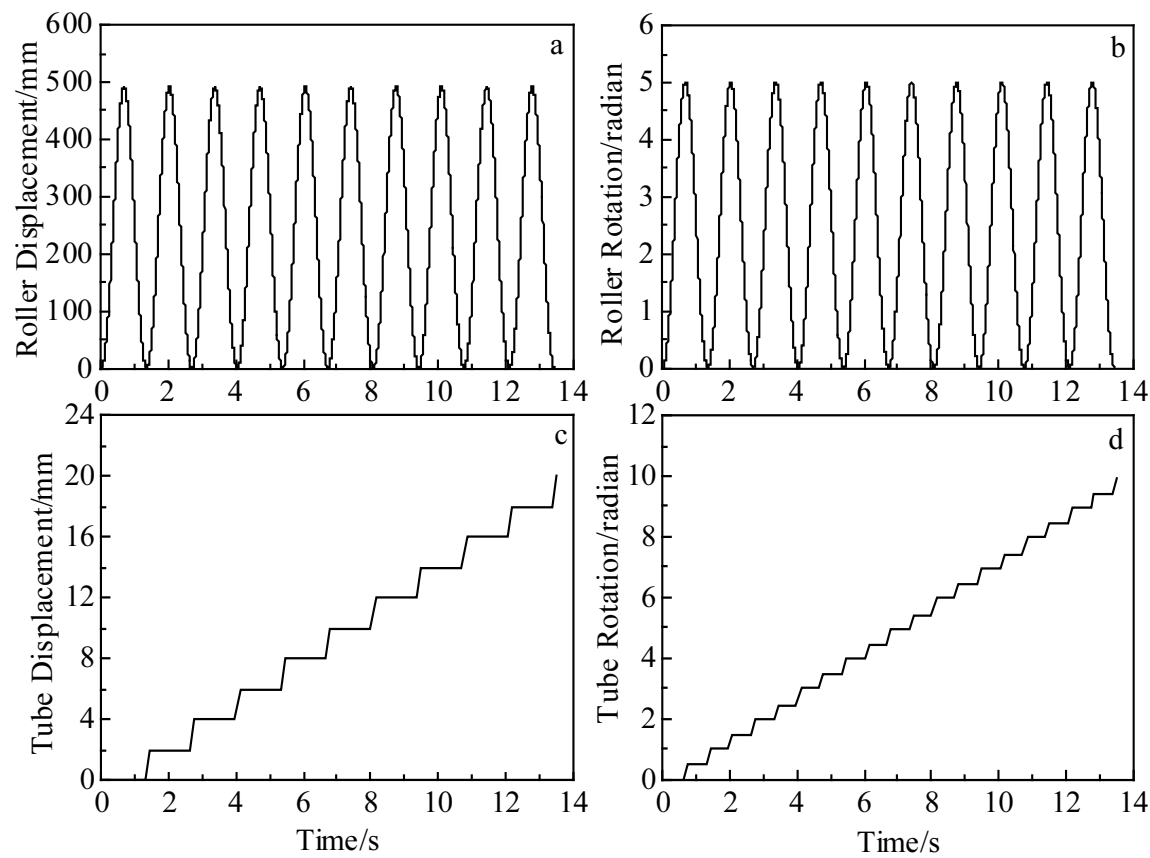

Fig.3 Typical amplitude-time curves describing the movement of roller and tube: (a) translation-time curve of roller, (b) rotation-time curve of roller, (c) translation-time curve of tube, and (d) rotation-time curve of tube

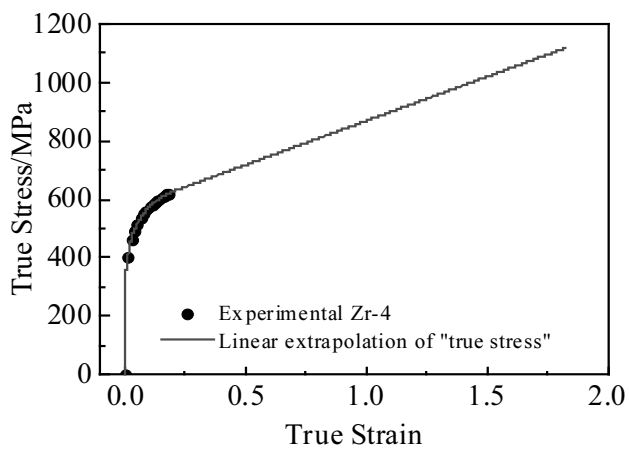

Fig.4 True stress-true strain curve of Zr-4 alloy

the mandrel), which means part of the tube reaches the target size and representative Pilger rolling simulation is achieved. The profiles of tube before and after rolling are displayed in Fig.5. For the sake of convenience, the deformed tube is divided into three areas. Thearea where the main deformation is diameter reduction is denoted AI. While, the region where diameter reduction and wall thickness reduction occur simultaneously is marked AII. The size fixing area is called AIII. These three areas are schematically shown in Fig.5.

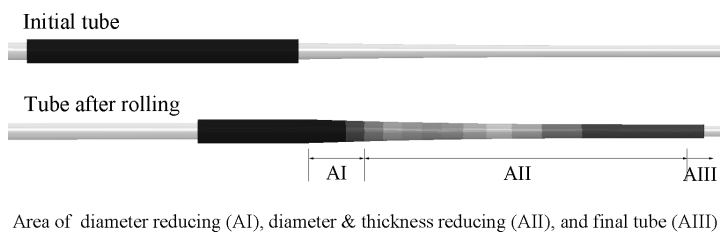

Fig.5 Profile of tube before and after partial (or interrupted) rolling
To evaluate the accuracy of the built model, the simulated tube sizes were compared with the experimental results. The simulated sizes, including outer diameter and wall thickness, were measured four times along different directions as shown in Fig.6. The predicted and experimental sizes are summarized in Table 1. It indicates that the deviations of the simulated sizes from the experimental results are very small $(0.4 \%$ and $6.4 \%$ for the diameter and wall thickness, respectively).

The rolling force can not be directly measured with the current Pilger rolling machine due to the lack of space for pressure sensor. Therefore, we compared the finite element simulated rolling force with the value calculated with a classic

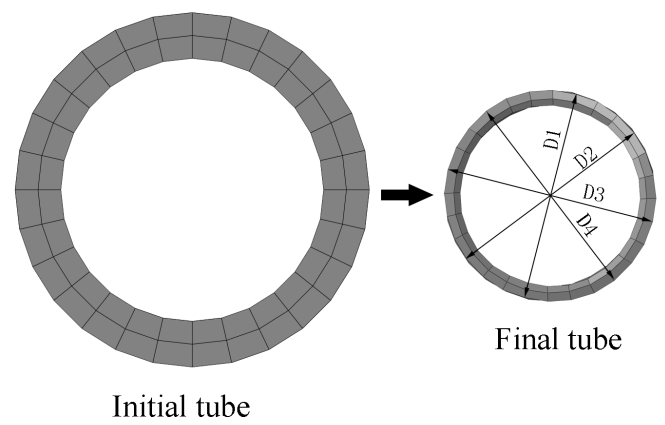

Fig.6 Cross section of tube before and after rolling

Table 1 Experimental and simulated sizes of the final tube Outer diameter/ Deviation/ Wall thickness/ Deviation/

\begin{tabular}{ccccc} 
& $\mathrm{mm}$ & $\%$ & $\mathrm{~mm}$ & $\%$ \\
\hline Experiment & $10.0 \pm 0.035$ & & $0.70 \pm 0.04$ & \\
Simulation & $10.04 \pm 0.02$ & 0.40 & $0.745 \pm 0.03$ & 6.40 \\
\hline
\end{tabular}


empirical formula. The used empirical formula ${ }^{[18]}$ is:

$$
\bar{p}_{\Sigma}=K_{\alpha} K_{\sigma} \sigma_{\mathrm{b} 50}\left(D_{0}+D_{1}\right) \sqrt{m \lambda_{\Sigma}\left(S_{0}-S_{1}\right) \bar{\rho}_{\mathrm{d}} / L_{\mathrm{g}}^{\prime}}
$$

where: $K_{\alpha}$-taper influence coefficient, when $\tan \alpha<0.02, K_{\alpha}=1$; $K_{\sigma}$-work hardening coefficient, for zirconium alloy, $K_{\sigma}=1.1$; $\sigma_{\mathrm{b} 50}$-flow strength of material at $50 \%$ deformation; $D_{0}$, $D_{1}$-initial and final diameter of the tube; $m$-feeding distance; $\lambda_{\Sigma}$-total extension coefficient; $S_{0}, S_{1}$-initial and final wall thickness of tube; $\bar{\rho}_{\mathrm{d}}$ - averge radius of groove-bottom, $\bar{\rho}_{\mathrm{d}}=\rho_{0}-0.5\left(R_{0}-R_{1}\right) ; R_{0}, R_{1}$-initial and final radius; $L_{\mathrm{g}}^{\prime}$ length of groove.

With the corresponding parameter values, the average rolling force of forward stroke calculated by the empirical formula is:

$$
\begin{aligned}
\bar{p}_{\Sigma}= & 1.0 \times 1.1 \times 777 \times(17.78+10.02) \times \\
& \sqrt{2 \times 5.32 \times(2.3-0.72) \times 96.05 / 250} \\
= & 60.3 \mathrm{kN}
\end{aligned}
$$

The rolling force simulated by the finite element model at different rolling time is shown in Fig.7. With more and more material going in deformation area (AI and AII), the peak rolling force increases gradually due to the material hardening at large strain. Moreover, when material goes to deformation area AII, the inner surface of the tube starts to contact with the mandrel. The frictional force between the tube and the mandrel also causes higher rolling force. To evaluate the average rolling force, the force-time curve of the last two strokes is used, as indicated in the enlarged view of Fig. 7. To obtain the average rolling force, the area covered by the force-time curves is firstly calculated and then divided by the time period. According to this method, the average rolling force is 55.0 and $35.6 \mathrm{kN}$ for the forward and backward stroke, respectively. By comparing the rolling force by empirical formula and that by finite element simulation, we conclude that the built finite element model can describe the rolling process very well.

\section{Deformation Behavior}

\subsection{Stress and strain state}

As indicated in Fig.5, there are three areas in the deformation region of the tube. Material points in different areas experience different stress states. For the material in AI, where diameter contraction is the main deformation, the distribution of stress and strain in a typical cross section are shown in Fig.8. Note that all the stress or strain components are expressed in a cylindrical coordinate. "1", "2" and "3" represents the radial direction, tangential direction and longitudinal direction, respectively. S11, S22 and S33 stand for normal stress component along radial direction, tangential direction and longitudinal direction, respectively. While, LE11, LE22 and LE33 means normal true strain in radial direction, tangential direction and longitudinal direction, respectively.

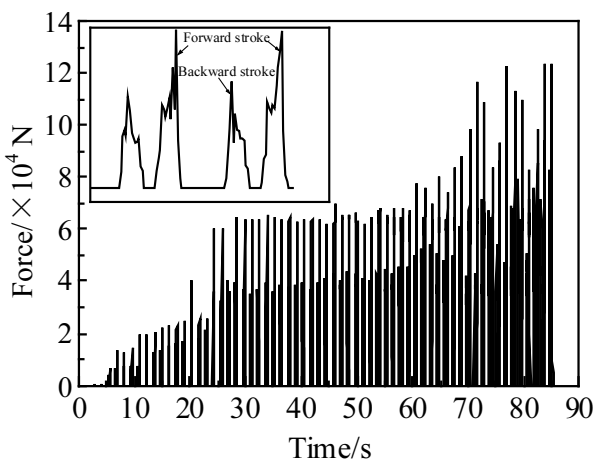

Fig.7 Simulated rolling force during the Pilger rolling of Zr-4 alloy
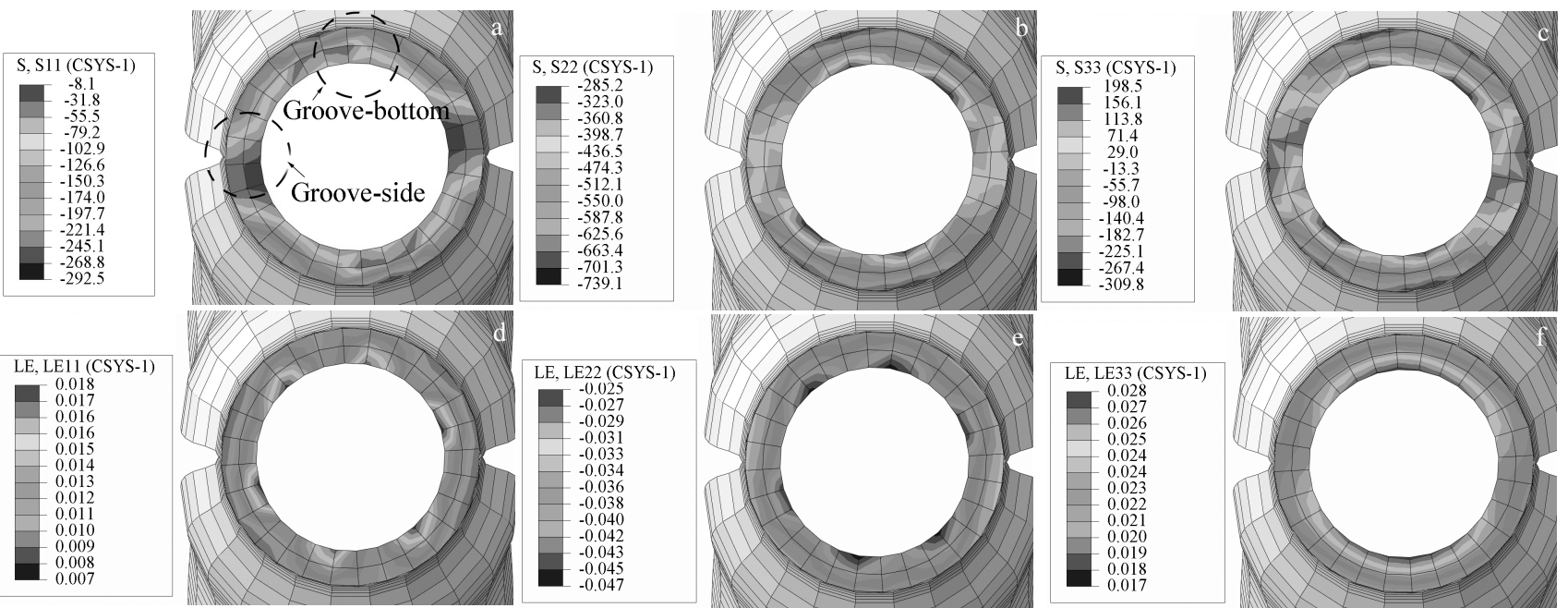

Fig.8 Distributions of strain and stress in the area of diameter reducing (AI): (a) normal stress component along radial direction, (b) normal stress component along tangential direction, (c) normal stress component along longitudinal direction, (d) normal strain component along radial direction, (e) normal strain component along tangential direction, and (f) normal strain component along longitudinal direction 
As can be seen in Fig.8, the material in groove-side endures compressive tangential stress and tensile longitudinal stress. The stress along radial direction is very small. On the outer surface of groove-bottom, all the stress components are compressive. While, tensile longitudinal stress is applied to the material on the inner surface of groove-bottom.

Compared with the stress state, the strain state in $\mathrm{AI}$ is relatively simple, as displayed in Fig.8d 8f. The wall thickness and the length of the tube are increased (tensile strain in radial and longitudinal direction) while the diameter is reduced (compressive strain in tangential direction).

The distribution of stress and strain on a typical cross section of AII, where wall thickness and diameter are reduced simultaneously, are displayed in Fig.9. For material in groove-bottom, all the stress components are compressive. However, the tangential stress component is compressive and the longitudinal stress component is tensile for material in groove-side. As shown in Fig.9d 9f, compressive strains are along radial and tangential directions while tensile strain is in longitudinal direction, which means the wall thickness and the diameter are reduced while the length is elongated.

\subsection{Normal strain history}

Elements at the front end of the tube have experienced all the stages of deformation, including diameter contraction, wall thickness reduction and size fixing. By analysing the deformation history of these elements, the deformation of the tube during Pilger rolling is followed. The evolution of normal strains of one typical element at the front end of the tube was exported and displayed in Fig.10. It is found that the tangential strain (LE22) and the longitudinal strain (LE33) gradually increase (in absolute value) during rolling until the element reaches the size fixing. However, the radial strain is firstly

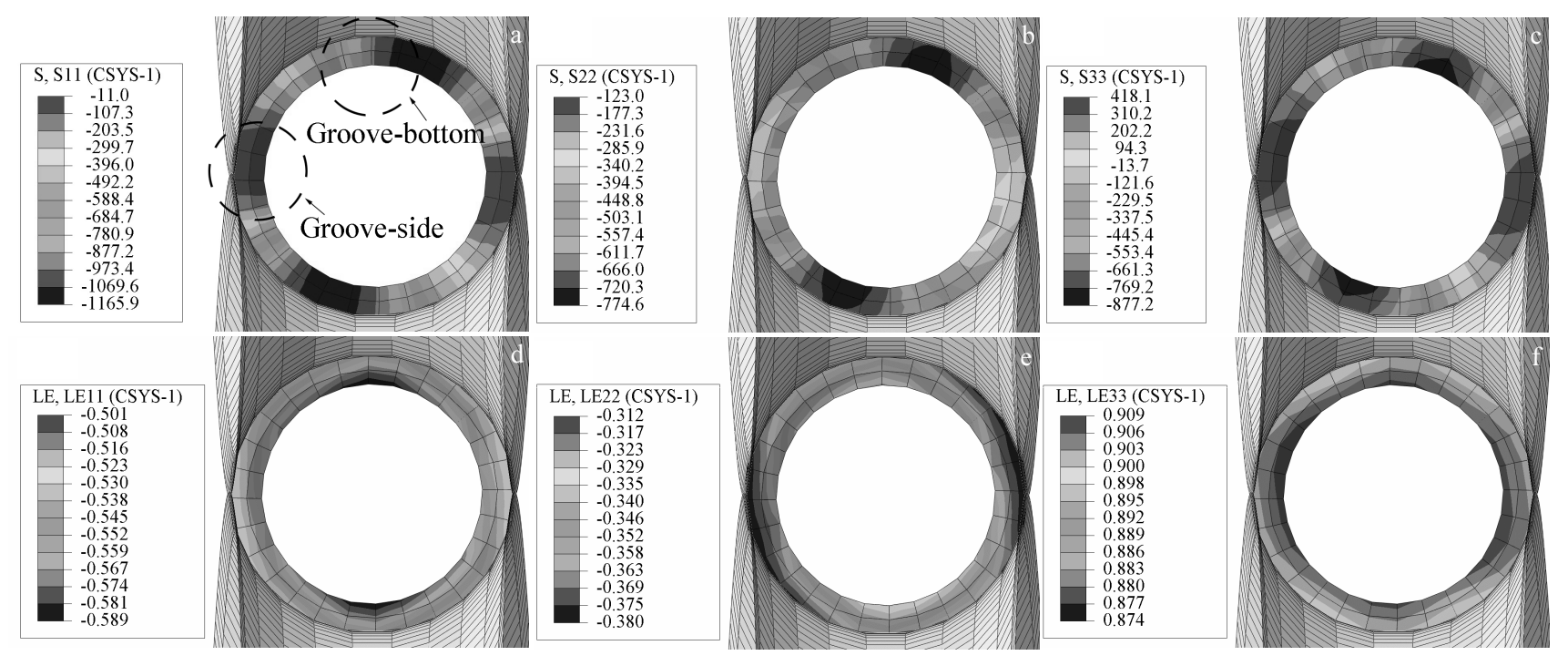

Fig.9 Distributions of strain and stress in the area of diameter \& thickness reducing (AII): (a) normal stress component along radial direction, (b) normal stress component along tangential direction, (c) normal stress component along longitudinal direction, (d) normal strain component along radial direction, (e) normal strain component along tangential direction, and (f) normal strain component along longitudinal direction

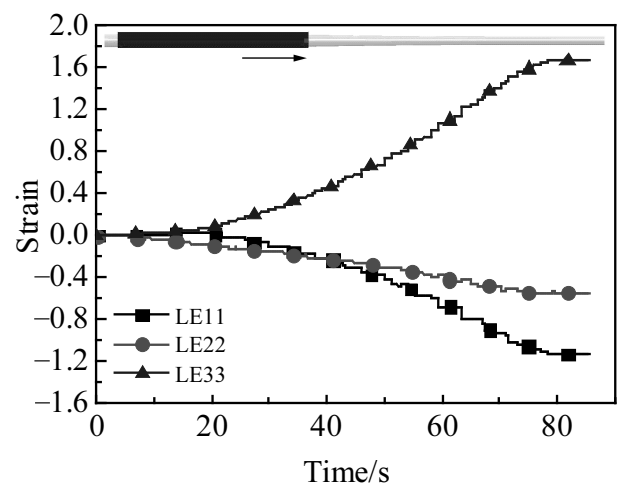

Fig.10 Evolutions of various strain components during Pilger rolling of Zr-4 alloy tensile and becomes compressive. As mentioned before, the $Q$-factor is defined as the ratio of radial strain on tangential strain and has a great infulence on the texture of the rolled tube. Judging by the initial $(\Phi 17.78 \mathrm{~mm} \times 2.30 \mathrm{~mm})$ and the final $(\Phi 10.02 \mathrm{~mm} \times 0.72 \mathrm{~mm})$ tube size, the total $Q$-factor is larger than $1(Q>1)$. However, according to the deformation history shown in Fig.10, the $Q$-factor is not always larger than 1. Actually, the $Q$-factor is firstly smaller than $1(Q<1)$ in AI and becomes larger than $1(Q>1)$ in AII. As reported in previous studies ${ }^{[7]}$, the main texture of the tube is a radial texture (with the basal plane almost perpendicular to the radial direction) if $Q>1$ while it will be a tangential texture if $Q<1$. Therefore, with the current rolling process, the tube will firstly develop a tangential texture and then a radial texture if the 
initial orientation is random.

\subsection{Shear strain}

Fig.11a shows the morphology of the deformed tube after Pilger rolling. Mesh distortion can be observed in the deformation area, which is the result of shear strain. Fig. 11b displays the shear strain of one element at the front end of the tube as a function of time. With increasing rolling time, shear strain generally increases. However, obvious fluctuations (cyclic shear deformation) exist. The maximum shear strain can reach 0.17 and has a final stable value of 0.12 . As reported by Girard et al. ${ }^{[6]}$, shear strain has a significant influence on the damage and texture of the tube. The cyclic shear deformation that appears in Fig. 11b may cause more severe damage on the tube, fatigue damage for instance. For clarity, one of shear strain cycle is amplified and presented in the upper left corner of Fig.11b. Each inflection is numbered.

To explore the underlying principle of fluctuations of the shear strain, the spatial location of the element was analyzed. Fig.12 shows the spatial location of the element when the shear strain changes. In Fig. 11b, the shear strain is increased from "1" to "2". At this time, the element is located at the up-right part of the groove-side, as shown in Fig.12a. We can speculate that there will be counterclockwise flow for this element when roller passes due to the oval groove. From "5" to "6", the shear strain decreases, as indicated in Fig.11b. At this time, the element lies in the low-right part of the groove-side and clockwise flow will occure if the roller passes. That implies that counterclockwise flow corresponds to the increase of shear strain while clockwise flow corresponds to the decrease of shear strain. The same observation is made when the element is located at other place, as shown in Fig. 12e and 12f. Therefore, we conclude that the fluctuations of shear strain are caused by the variations of the relative position of element (material point) with respect to the groove-side. The variations of element's relative position result from the cyclic rotations of the tube during Pilger rolling.
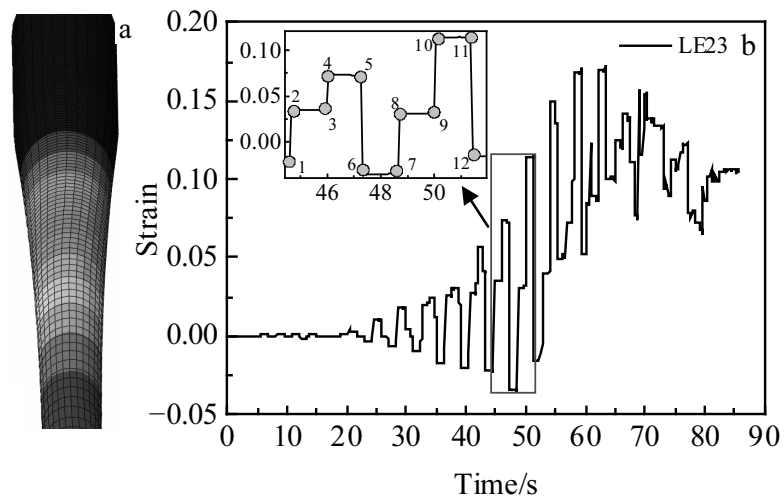

Fig.11 Shear deformation of the tube after Pilger rolling: (a) the distorsion of mesh and (b) shear strain evolution as a function of time
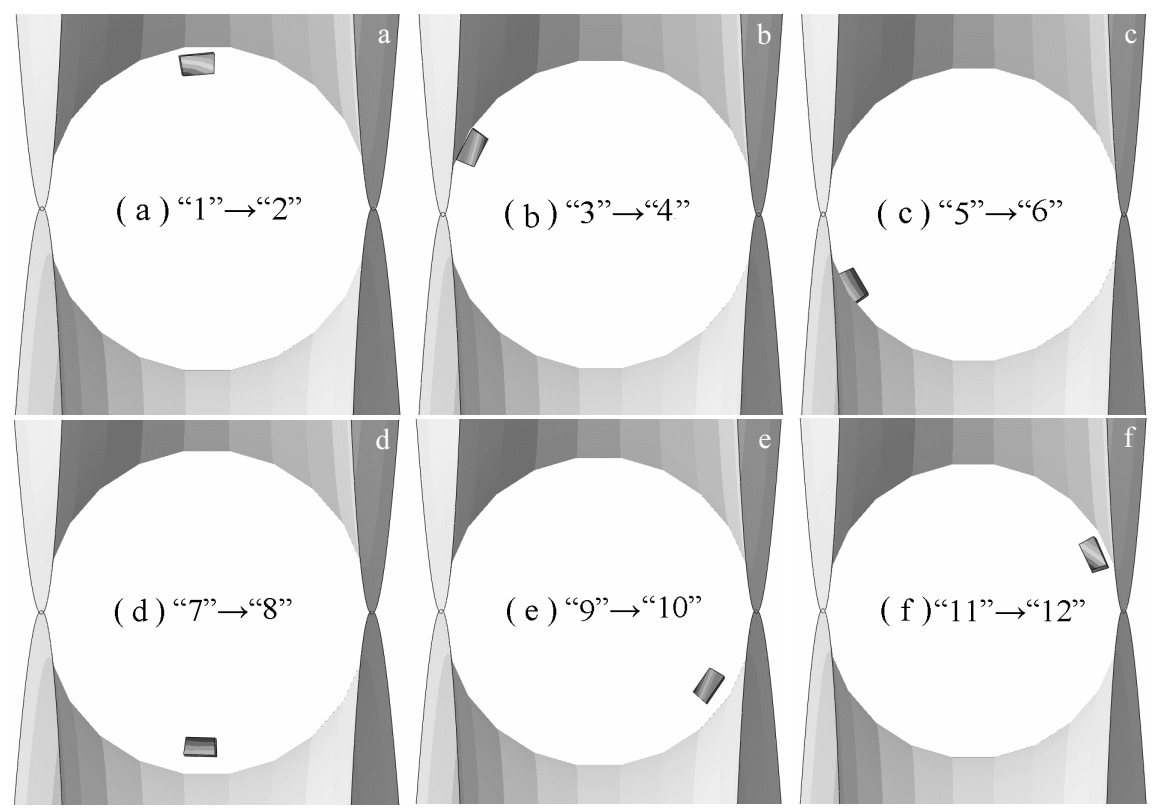

Fig.12 Location evolution of the element shown in Fig. 11b at different rolling time

\section{Conclusions}

1) A finite element model for Pilger rolling of $\mathrm{Zr}-4$ tube was built and simulation of a full pass of rolling, including more than 70 forward and backward stokes, was carried out. The built model was validated by comparing the predicated tube sizes and the rolling force with experimental sizes and analytically calculated rolling force, respectively.

2) In different deformation areas, material undergoes different strain states. The area of diameter reduction is characterized by tensile strain in radial and longitudinal direction while compressive strain in tangential direction. In 
the area of diameter \& wall thickness reduction, material elements endure tensile strain in longitudinal direction while compressive strain in radial and tangential direction.

3) In different parts, material experiences different stress states. In the groove-bottom, compressive stresses are along three directions while in the groove-side the longitudinal direction is under tensile stress and the tangential direction is in compression.

4) Obvious fluctuant (cyclic) shear strain is predicted for the element (material point) at the front end of the tube. The fluctuations of the shear strain are caused by the variations of the relative position of the element with respect to the groove-side. The variations of element's relative position result from the cyclic rotations of the tube during Pilger rolling.

\section{References}

1 Linga Murty K, Charit I. Progress in Nuclear Energy[J], 2006, 48: 325

2 Wang Xuefeng, Li Zhongkui, Zhou Jun et al. Material \& Heat Treatment [J], 2012, 41: 71 (in Chinese)

3 Liu Wenqing, Zhong Liuming, Peng Jianchao et al. Rare Metal Materials and Engineering[J], 2011, 40(7): 1216 (in Chinese)

4 Zou Dongli, Luan Baifeng, Xiao Dongping. Rare Metal Materials and Engineering[J], 2014, 43(8): 1897 (in Chinese)

5 Montmitonnet P, Farrugia D, Aubin J L et al. Wear[J], 1992, 152: 327

6 Girard E, Guillén R, Weisbecker P et al. Journal of Nuclear
Materials[J], 2001, 294: 330

7 Allen V M, Preuss M, Robson J D et al. Textures of Materials, Pts 1 and 2[M]. Zurich-Uetikon: Trans Tech Publications Ltd, 2005: 675

8 Abe H, Furugen M. Materials Transaction[J], 2010, 51: 1200

9 Abe H, Furugen M. Journal of Materials Processing Technology [J], 2012, 212: 1687

10 Mukherjee P, Gayathri N, Chowdhury P S et al. Journal of Nuclear Materials[J], 2013, 434: 24

11 Aubin J L, Montmitonnet P, Mulot S. Zirconium in the Nuclear Industry: Twelfth International Symposium[M]. W Conshohocken: American Society Testing and Materials, 2000: 460

12 Mulot S, Hacquin A, Montmitonnet P et al. Journal of Materials Processing Technology[J], 1996, 60: 505

13 Montmitonnet P, Logé R, Hamery M et al. Journal of Materials Processing Technology[J], 2002, 125-126: 814

14 Lodej B, Niang K, Montmitonnet P et al. Journal of Materials Processing Technology[J], 2006, 177: 188

15 Gurao N P, Akhiani H, Szpunar J A. Journal of Nuclear Materials[J], 2014, 453: 158

16 Huang Liang, Xu Zhe, Dai Chun et al. Rare Metal Materials and Engineering [J], 2013, 42(3): 524 (in Chinese)

17 Huang Liang, Xu Zhe, Dai Chun et al. Rare Metal Materials and Engineering [J], 2013, 42(4): 741 (in Chinese)

18 Huai Xian. Metal Plastic Processing: Extrusion, Drawing and Cold-Rolled Pipes[M]. Beijing: Metallurgical Industry Press, 1991: 263 (in Chinese)

\title{
Zr-4 合金管材皮尔格轧制过程数值模拟分析：宏观模型的建立、验证及塑性变形分析
}

\author{
何维均 ${ }^{1,2}$, 袁改焕 ${ }^{2,3}$, 奕佰峰 ${ }^{1}$, 王 练 ${ }^{2,3}$, 储林华 ${ }^{2}$, 刘 庆 $^{1}$ \\ (1. 重庆大学, 重庆 400044)
}

(2. 国核宝钛锆业股份公司，陕西 宝鸡 721013)

(3. 陕西省核级锆合金重点实验室，陕西 宝鸡 721013)

\begin{abstract}
摘 要: 皮尔格轧制变形对于锆合金管材的性能有着重要影响, 受到学者们的高度重视。长期以来，由于皮尔格轧制是一个高度非线性 的三维变形过程, 开展实验研究不但成本高昂而且周期较长。本研究以 ABAQUS/standard 平台, 根据多行程皮尔格轧制的运动特点, 建立了 Zr-4 合金管材皮尔格轧制有限元模型, 并开展一整个道次的轧制过程模拟。模拟结果表明: 预测的管材几何尺寸与实验结果吻 合良好，而模拟的轧制力与经典的舍瓦金公式计算结果也比较相符，验证了所建立模型的准确性，可用于进一步仿真分析。模拟结果还 表明开口处的管坏应力状态与轧槽底部管坏的应力状态有显著的差别。此外, 轧制过程中还存在有明显的剪切变形, 而且还有较大幅度 的周期性波动, 这主要与孔型开口以及管坏回转送进有关。
\end{abstract}

关键词: 锆合金; 皮尔格轧制; 有限元模拟; 塑性变形

作者简介: 何维均, 男, 1984 年生, 博士, 重庆大学材料科学与工程学院, 重庆 400044, 电话: 023-65106067, E-mail: weijun.he@cqu.edu.cn 